\title{
ISPITIVANJE NOVOG POSTUPKA SINTEZE SCHIFF-OVE BAZE U MIKROREAKTORSKOM SISTEMU
}

\section{STUDY OF A NEW PROCEDURE FOR THE SYNTHESIS OF SCHIFF BASE IN A MICROREACTOR SYSTEM}

\author{
Julijana TADIĆ ${ }^{*}$, Petra PAVLOVIĆ ${ }^{2}$, Marina MIHAJLOVIĆ ${ }^{1}$, \\ Dušan MIJIN ${ }^{2}$, Mića JOVANOVIĆ ${ }^{1,3}$ \\ ${ }^{1}$ Inovacioni centar Tehnološko-metalurškog fakulteta u Beogradu, Beograd; \\ 2 Tehnološko-metalurški fakultet u Beogradu, Univerzitet u Beogradu, Beograd; \\ ${ }^{3}$ Akademija inzenjerskih nauka Srbije
}

https://doi.org.10.240/ptk.018.31.1.23

Organska sinteza u kontinualnim sistemima privlači sve više pažnje kako u naučnim istraživanjima tako $i$ u industriji. U laboratorijskim uslovima kontinualni metod sinteze najčešće podrazumeva upotrebu mikroreaktora. Ključna prednost mikroreaktora u odnosu na klasične šaržne reaktore jeste veliki odnos površine i zapremine, koji omogućava bolji prenos mase i toplote, veći stepen konverzije, skraćeno vreme trajanja reakcije, bezbednu, jednostavnu i preciznu regulaciju procesa. U ovom radu ispitivana je sinteza Schiff-ove baze u kontinualnom mikroreaktorskom sistemu, na sobnoj temperaturi. U cilju ostvarenja što većeg prinosa proizvoda varirane su koncentracije rastvora polaznih reaktanata $i$ vreme zadržavanja $u$ mikroreaktoru. Reakcija je kvalitativno praćena na UV-Vis spektrofotometru. Sintetisani benzilidenanilin okarakterisan je temperaturom topljenja i FT-IR podacima.

\section{Ključne reči: Benzilidenanilin; Kontinualna sinteza; Mikroreaktor}

Continuous flow synthesis attracts extended attention in academia as well as in the industry. In laboratory conditions, the continuous flow method usually involves the use of microreactors. The key advantage of microreactors compared to classical batch reactors is the large volume to surface ratio which allows a better mass and heat transfer, higher conversion rate and shorter reaction time as well as safe, simple and precise process control. In this paper the synthesis of Schiff base in a continuous flow microreactor system, at room temperature was examined. In order to achieve higher product yield, the concentrations of the starting materials and the retention time in the microreactor were varied. The reaction was followed by UV-Vis spectrophotometry. The synthesized benzylideneaniline was characterized by melting point and FT-IR data.

Key words: Benzylideneaniline; Continuous flow synthesis; Microreactor

\section{Uvod}

Iako živimo u vremenu naprednih tehnologija i svakodnevnih tehnoloških inovacija, organska sinteza se i danas najčešće izvodi na tradicionalan način. Ukoliko se govori o organskoj sintezi u industriji, reakcije se uglavnom odigravaju u šaržnim reaktorima, uz primenu visoke temperature, pritiska i velike potrošnje organskih reagenasa i rastvarača potrebnih za prečišćavanje i dobijanje finalnog proizvoda [1]. U laboratorijskim uslovima, organska sinteza se najčešće izvodi u čaši ili balonu, uz refluks i mešanje, što je nepovoljno sa strane utroška energije, reaktanata, dugog vremenskog perioda potrebnog za dobijanje krajnjeg proizvoda i bezbednosti istraživača na radu [1]. Sinteza u kontinualnim protočnim sistemima predstavlja dobru alternativu klasičnim postupcima dobijanja organskih jedinjenja [2]. U laboratorijskim uslovima kontinualni metod sinteze najčešće podrazumeva upotrebu mikroreaktora. U mikroreaktorima hemijska reakcija se odigrava u zatvorenom prostoru mikrometarskih prečnika, pod strogo kontrolisanim uslovima, što omogućava bolji prenos mase i toplote, a samim tim i poboljšanu produktivnost u kraćem vremenskom periodu [2,3]. Zahvaljujući automatizovanoj regulaciji procesa i upotrebi malih zapremina reaktanata obezbeđuje se olakšano i bezbedno rukovanje, pogotovo ako se koriste toksični ili nestabilni reagensi $[1,4]$. Kontinualni metod sinteze u mikroreaktoru, može jednostavno da se kombinuje i sa drugim tehnologijama, kao što je mikrotalasno zračenje, što čini proces još efikasnijim [1]. Takođe, u poređenju sa šaržnim sistemima olakšano je uvećanje razmera procesa i prelazak sa laboratorijskog na industrijski nivo [5].

Sinteza Schiff-ovih baza je vrlo atraktivna već decenijama unazad zbog jednostavnog dobijanja i široke primene ovih jedinjenja u industriji pigmenata, boja, katalizatora i polimera [6]. Klasična sinteza ovih jedinjenja zasniva se na reakciji kondenzacije između primarnih amina i aldehida ili ketona [7]. Dalje, Schiff-ove

*Autor za korespondenciju: jtadic@tmf.bg.ac.rs 
baze, kao i njihovi metalni kompleksi poseduju izuzetnu katalitičku i biološku (antimikrobnu, antiviralnu, antiinflamatornu i antioksidativnu) aktivnost te se koriste u medicini i farmaciji $[6,8]$.

U ovom radu izvršena je sinteza Schiff-ove baze, benzilidenanilina, u kontinualnom mikroreaktorskom sistemu, na sobnoj temperaturi, u veoma kratkom vremenskom periodu. Benzilidenanilin sintetisan je iz rastvora benzaldehida i anilina, $u$ etanolu, u kiseloj sredini (par kapi sirćetne kiseline). Dobijeni proizvod je okarakterisan temperaturom topljenja, UV-Vis, FT-IR podacima. Nedostaci sinteze klasičnim postupkom su primena visoke teperature, produženo vreme trajanja reakcije i dodatni utrošak rastvarača za prečišćavanje krajnjeg proizvoda. Upotrebom kontinualnog mikroreaktorskog sistema prevazilaze se ovi nedostaci, sinteza se vrši na sobnoj temperaturi i dobija se čist proizvod u kratkom vremenskom periodu.

\section{Eksperimentalni deo}

Sinteza Schiff-ove baze, benzilidenanilina, izvedena je u kontinualnom mikroreaktorskom sistemu, na sobnoj temperaturi, polazeći od komercijalno dostupnih materijala (Sigma Aldrich). Dobijeni benzilidenanilin sintetisan je iz anilina i benzaldehida rastvorenih u etanolu, u kiseloj sredini (par kapi sirćetne kiseline), $u$ molskom odnosu 1:1 (slika 1). Hemijska struktura i čistoća dobijenog proizvoda, potvrđena je temperaturom topljenja, UV-Vis i FT-IR podacima. Temperatura topljenja je određena na Elektrothermal aparatu. Infracrveni spektri jedinjenja su snimljeni na Bomem MB 100 spektrofotometru u oblasti od $4000-400 \mathrm{~cm}^{-1} \mathrm{u}$ formi KBr tableta.

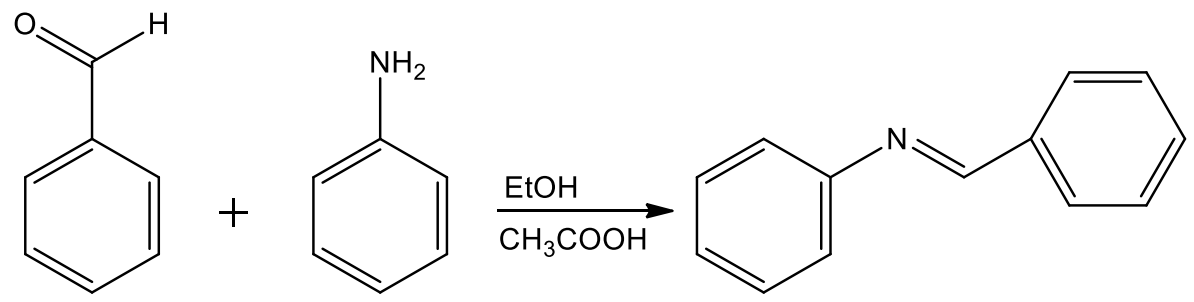

Slika 1. Reakcija dobijanja benzilidenanilina

Kontinualni mikroreaktorski sistem je sačinjen iz dve HPLC pumpe (LC-20AD XR, Shimadzu Usa Manufacturing Inc.), T miksera i mikroreaktora (slika 2). Mikroreaktor je kapilarno crevo izgrađeno od PTFE materijala (Sigma Aldrich, dužina: $50 \mathrm{ft}(\sim 15 \mathrm{~m})$, unutrašnji prečnik: 0,5 mm, zapremina: $\left.3 \mathrm{~cm}^{3}\right) . \mathrm{T}$ mikser povezuje izlaze iz pumpi A i B i mikroreaktor. Reakciona smeša prolazi kroz mikroreaktor, u kome se odigrava reakcija kondenzacije na sobnoj temperaturi, i na izlazu dospeva u prihvatni sud sa natrijumhidroksidom, koji ima ulogu inhibitora reakcije.

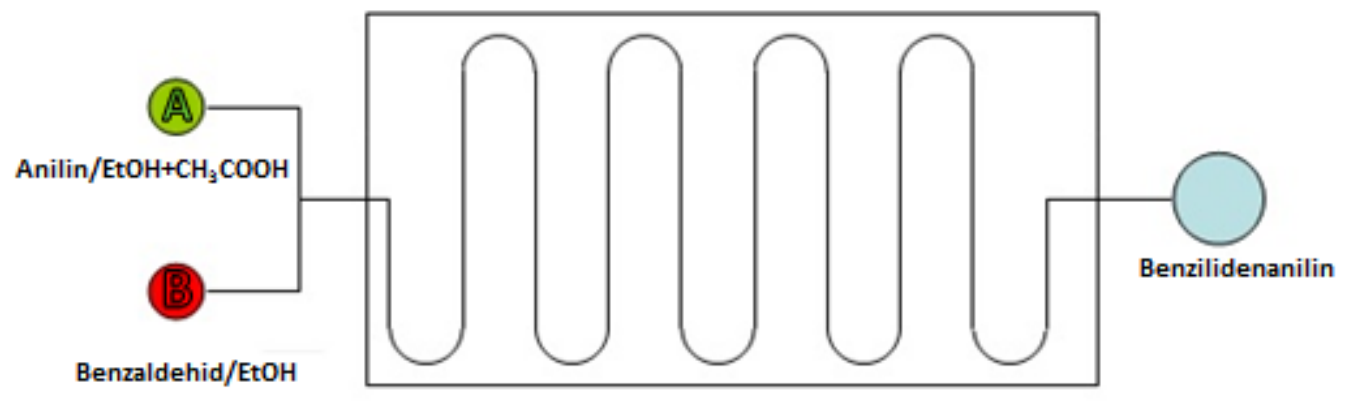

Slika 2. Šema kontinualnog mikroreaktorskog sistema

U funkciji optimizacije procesa izvedene su dve serije eksperimenata. U prvoj seriji pripremljeni su rastvori koncentracije $0,2 \mathrm{~mol} \cdot \mathrm{dm}^{-3}$ benzaldehida $\mathrm{i}$ anilina u etanolu, uz dodatak 3 kapi sirćetne kiseline, $u$ rastvor anilina. Rastvori su dovedeni pumpama u mikroreaktor, kao što je prethodno opisano i prikazano na slici 2. Reakcija kondenzacije izvedena je pri različitim protocima polaznih reaktanata, tako da je varirano vreme zadržavanja u mikroreaktoru. U drugoj seriji eksperimenata, sinteza benzilidenanilina je izvedena na isti način kao u prvoj seriji, s tim što je u cilju povećanja prinosa, povećana koncentracija rastvora polaznih jedinjenja na $1 \mathrm{~mol} \cdot \mathrm{dm}^{-3}$. Po završetku reakcije dobijeni proizvod se izdvaja u vidu svetložutih kristala koji se potom odvoje na Bihnerovom levku, ostave da se osuše, a zatim se okarakterišu: : t.t. 51-52 (lit. 50-52 [9]); FT-IR(KBr, $\left.v / \mathrm{cm}^{-1}\right): 1625(\mathrm{C}=\mathrm{N})$, UV-Vis $\left(\mathrm{EtOH}, \lambda_{\max } / \mathrm{nm}\right): 260 \mathrm{~nm}$.

Uporedo sa sintezom u kontinualnom sistemu, izvedena je i klasična sinteza benzilidenanilina. Anilin (30 mmol), benzaldehid (30 mmol), etanol $(25 \mathrm{ml})$ i 5 kapi sirćetne kiseline se pomešaju u balonu opremljenom povratnim kondenzatorom. Reakciona smeša se zagreva uz refluks i mešanje 2 sata [9]. Dobijeni svetlo- 
žuti kristali se izdvoje na Bihnerovom levku i prekristališu iz dietiletra: t.t. $48-53{ }^{\circ} \mathrm{C}$ (lit. $50-52{ }^{\circ} \mathrm{C}$ [9]), prinos: $80 \%$.

\section{Rezultati i diskusija}

U prvoj seriji eksperimenata sinteza benzilidenanilina, u kontinualnom mikroreaktorskom sistemu, izvedena je na sobnoj temperaturi, kako je prethodno opisano, pri koncentraciji rastvora polaznih reaktanata od $0,2 \mathrm{~mol} \cdot \mathrm{dm}^{-3}$ i protocima prikazanim u Tabeli 1 .

Tabela 1. Optimizacija protoka u prvoj seriji eksperimenata sinteze benzilidenanilina u kontinualnom mikroreaktorskom sistemu

\begin{tabular}{|c|c|c|c|c|c|c||}
\hline \hline Redni broj eksperimenta & $F(A)\left[\mathrm{cm}^{3} \cdot \mathrm{min}^{-1}\right]$ & $F(B)\left[\mathrm{cm}^{3} \cdot \mathrm{min}^{-1}\right]$ & $F_{T}\left[\mathrm{~cm}^{3} \cdot \mathrm{min}^{-1}\right]$ & $\tau[\mathrm{min}]$ & $V\left[\mathrm{~cm}^{3}\right]$ & $Y[\%]$ \\
\hline 1. & 0,05 & 0,05 & 0,10 & 30 & 4,50 & 40 \\
\hline 2. & 0,07 & 0,07 & 0,14 & 21 & 4,50 & 45 \\
\hline 3. & 0,10 & 0,10 & 0,20 & 15 & 4,50 & 60 \\
\hline 4. & 0,30 & 0,30 & 0,60 & 5 & 4,50 & 45 \\
\hline 5. & 0,50 & 0,50 & 1,00 & 3 & 4,50 & 40 \\
\hline
\end{tabular}

*F (A) - protok rastvora anilina u etanolu sa tri kapi sirćetne kiseline

* F (B) - protok rastvora benzaldehida u etanolu

$* \mathrm{~F}_{\mathrm{T}}-$ ukupni protok reakcione smeše u mikroreaktoru

$* \tau$ - vreme zadržavanja u mikroreaktoru

$* \mathrm{~V}$ - zapremina reakcione smeše

$* \mathrm{Y}-$ prinos

Rezultati prikazani u Tabeli 1 pokazuju da se najviši prinos postiže ukoliko se reakcija izvodi u trajanju od 15 minuta, pri ukupnom protoku reakcione smeše od $0,20 \mathrm{~cm}^{3} \cdot \min ^{-1}$. Dodatnim povećanjem protoka smanjuje se stepen konverzije, što za posledicu ima smanjenje prinosa i čistoće željenog proizvoda.

U cilju povećanja prinosa pripremljeni su novi rastvori polaznih jedinjenja koncentracije $1 \mathrm{~mol} \cdot \mathrm{dm}^{-3}$. Rezultati dobijeni u ovoj seriji prikazani su u Tabeli 2.

Tabela 2. Optimizacija protoka u drugoj seriji eksperimenata sinteze benzilidenanilina u kontinualnom mikroreaktorskom sistemu

\begin{tabular}{|c|c|c|c|c|c|c|}
\hline \hline Redni broj eksperimenta & $F(A)\left[\mathrm{cm}^{3} \cdot \mathrm{min}^{-1}\right]$ & $F(B)\left[\mathrm{cm}^{3} \cdot \mathrm{min}^{-1}\right]$ & $F_{T}\left[\mathrm{~cm}^{3} \cdot \mathrm{min}^{-1}\right]$ & $\tau[\mathrm{min}]$ & $V\left[\mathrm{~cm}^{3}\right]$ & $Y[\%]$ \\
\hline 1. & 0,05 & 0,05 & 0,10 & 30 & 4,50 & 60 \\
\hline 2. & 0,07 & 0,07 & 0,14 & 21 & 4,50 & 55 \\
\hline 3. & 0,10 & 0,10 & 0,20 & 15 & 4,50 & 55 \\
\hline 4. & 0,30 & 0,30 & 0,60 & 5 & 4,50 & 60 \\
\hline 5. & 0,50 & 0,50 & 1,00 & 3 & 4,50 & 85 \\
\hline
\end{tabular}

*F $(\mathrm{A})$ - protok rastvora anilina u etanolu sa tri kapi sirćetne kiseline

* F (B) - protok rastvora benzaldehida u etanolu

$* \mathrm{~F}_{\mathrm{T}}$ - ukupni protok reakcione smeše u mikroreaktoru

$*_{\tau} \tau$ - vreme zadržavanja u mikroreaktoru

$* \mathrm{~V}$ - zapremina reakcione smeše

$* \mathrm{Y}-$ prinos

Iz rezultata prikazanih u Tabeli 2 uočava se da se povećanjem koncentracije polaznih rastvora reakcija znatno ubrzava. Naime, nakon samo 3 minuta zadržavanja u mikroreaktoru postignut je prinos benzilidenanilina od $85 \%$. Ovaj rezultat predstavlja znatni napredak u odnosu na klasičnu sintezu, gde se ovaj prinos postiže nakon 2 sata, uz primenu povišene temperature, dok se u kontinualnom sistemu reakcija odvija na sobnoj temperaturi, što omogućava uštedu, kako energije, tako i vremena potrebnog za izvođenje sinteze.

Ovim se potvrđuje efikasnost kontinualnog mikroreaktorskog sistema, u odnosu na klasični postupak sinteze. Dalje, benzilidenanilin dobijen u mikroreaktorskom sistemu nije naknadno prečišćavan, dok je nakon sinteze klasičnim postupkom bilo potrebno prekristalisati dobijeni proizvod, što iziskuje dodatni utrošak rastvarača i produžava vreme trajanja čitavog procesa dobijanja proizvoda. 


\section{Zaključak}

Cilj ovog rada je ispitivanje efikasnosti kontinualnog mikroreaktorskog sistema u sintezi Schiff-ove baze. U okviru rada sintetisana je Schiff-ova baza, benzilidenanilin, u mikroreaktoru, na sobnoj temperaturi. Ispitivan je uticaj promene vremena zadržavanja i koncentracije reaktanata u mikroreaktoru na prinos proizvoda. U prvoj seriji eksperimenata, pri koncentraciji rastvora polaznih jedinjenja od $0,2 \mathrm{~mol} \cdot \mathrm{dm}^{-3}$, najveći prinos benzilidenanilina od $60 \%$ ostvaren je pri ukupnom protoku reakcione smeše od $0,20 \mathrm{~cm}^{3} \cdot \mathrm{min}^{-1} \mathrm{i}$ vremenu zadržavanja u mikroreaktoru 15 minuta, a daljim povećavanjem protoka ustanovljeno je da prinos opada. Optimizacija postupka je nastavljena u drugoj seriji eksperimenata. Pripremljeni su rastvori pet puta veće koncentracije koja je iznosila $1 \mathrm{~mol} \cdot \mathrm{dm}^{-3}$. Najveći prinos od $85 \%$ ostvaren je pri protoku reakcione smeše od $1 \mathrm{~cm}^{3} \cdot \mathrm{min}^{-1}$ i vremenu zadržavanja u mikroreaktoru od samo $3 \mathrm{~min}$. Rezultati eksperimenta u kontinualnom mikroreaktorskom sistemu pokazuju da se za samo par minuta može uspešno sintetisati čist proizvod u dobrom prinosu, nasuprot klasičnoj sintezi koja pod istim uslovima traje 2 sata. Mikroreaktori su se pokazali kao obećavajući sistemi za organsku sintezu, čijom se upotrebom skraćuje vreme trajanja reakcije i postiže ušteda reaktanata i energije.

\section{Zahvalnica}

Istraživanja u ovom radu izvršena su u okviru aktivnosti na projektu TR 34009 koji finanansira Ministarstvo prosvete, nauke i tehnološkog razvoja Republike Srbije.

\section{Literatura}

[1] Porta, R., M. Benaglia, A. Puglisi, Flow Chemistry: Recent Developments in the Synthesis of Pharmaceutial Products, Organic Process Research and Development, 20 (2016), pp.2-25.

[2] Jovanovic, J., Liquid-liquid Microreactors for Phase Transfer Catalysis, Ph.D. thesis, Eindhoven University of Technology Library, Eindhoven, Netherlands 2011.

[3] Glasnov, T., Continuous-Flow Chemistry in the Research Laboratory, Springer International Publishing AG, Basel, Switzerland 2016.

[4] Roberge, D. M., L. Ducry, N. Bieler, P. Cretton, B. Zimmermann, Microreactor Technolo-gy: A Revolution for the Fine Chemical and Pharmaceutical Industries?, Chemical Engineering \& Technology, 28 (2005), pp.318-323.

[5] Lomel, S., L. Falk, J. M. Commenge, J. L. Houzelot, K. Ramdani, The microreactor. A systematic and efficient tool for the transition from batch to continuous process?, Chemical Engineering Research and Design, 84 (2006), pp. 363-369.

[6] Al Zoubi, W. Y. G. Ko, Schiff base complexes and their versatile applications as catalysts in oxidation of organic compounds: part I, Applied Organometallic Chemistry, 31 (2017), pp.1-12.

[7] Brodowska, K., E. Lodyga-Chruscinska, Schiff bases - interesting range of applications in various fields of science, Chemik, 68 (2014), pp.129-134.

[8] Silva, C. M., D. L. Silva, L. V. Modolo, R. B. Alves, M. A. Resende, C. V. B. Martins, A. Fatima, Schiff bases: A short review of their antimicrobial activities, Journal of Advanced Research, 2 (2011), pp.1-8.

[9] Hania, M. M., Synthesis of Some Imines and Investigation of their Biological Activity, E-Journal of Chemistry, 6 (2009), pp. 629-632. 